\title{
Load-bearing capacity of integrity reinforcement depending on change of the mechanical parameters of the steel
}

\author{
Barbara Wieczorek ${ }^{1^{*}}$ \\ ${ }^{1}$ Silesian University of Technology, Faculty of Civil Engineering, Gliwice, Poland
}

\begin{abstract}
The paper presents the results of numerical simulations performed on a simplified model of a slab-column connection. The aim of the investigations was to determine the value of the load at which the destruction of such a connection occurs due to a rupture of bars located above the column. In respective models, the column was situated axially or eccentrically with respect to span of bars. In each case the reinforcement passing above the column consisted of two bars. The analysis included a change in size, determining the most important parameters characterizing the properties of steel. The obtained results of calculations permitted to determine the relations between the exerted load and the displacement of the column. Based on the results, the load-bearing capacity of the reinforcing bars due to mechanical parameters of the steel was determined.
\end{abstract}

\section{Introduction}

Slab-column structures, because of their numerous advantages, are commonly utilized in housing, industrial and public utility buildings. Unfortunately, they have one drawback, namely the possibility of punching in the support zone. Standard guidelines EC2 [2] include procedures for determining the load-bearing capacity of this zone, taking into account the support dimensions and the possible extra vertical reinforcement. Nevertheless, as proven by the summary of several dozen building collapses included in [3], punching remains the main reason of failures in such structures. Hence, EC1 [1] standard provides guidelines for utilizing the integrity reinforcement as the simplest method of decreasing the scope of failure resulting from punching of the support zone. The subsequent part of the article is devoted to an attempt of numerical analysis of the load-bearing capacity of integrity reinforcement following the slab-column connection failure by punching, based on experimental research.

\section{Experimental research}

The experimental research $[4,5]$ revealed a very complex nature of the post-punching behavior of slab-column connections. It also provided a lot of interesting information

* Corresponding author: barbara.wieczorek.box@gmail.com 
on the subject. However, some unexplained issues remain which were impossible to define experimentally, the major being the inability to perform a detailed examination of the action of integrity reinforcement rods in the connection. In this case it was concluded that the deformation and load-bearing capacity they can provide would be revealed by means of a numerical simulation.

\section{The numerical model}

The computer simulation of the action of integrity reinforcement bars in experimental models was conducted using ANSYS. The numerical model was developed with reference to the experience of the authors of papers $[6,7,8,9,10]$ in the fields of: utilization of linear and non-linear material models, assuming the different-shaped type of finite elements, selection of their size for meshing, use of iterative calculation methods. The author's own analyses were included in publications $[11,12,13]$. They referred to the simulation of the behavior of integrity reinforcement bars in a state of significant deformation, pointing at numerous relevant factors which should be taken into account when mapping real phenomena. The analyses pertained both to technical aspects of modelling the structure of individual elements of the building and physical aspects that stem from modelling of steel and concrete properties.

a)

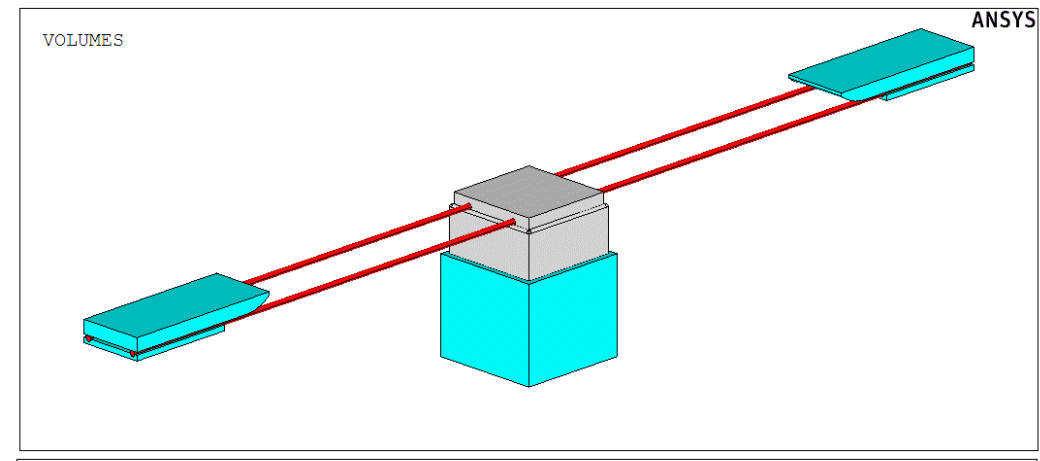

b)

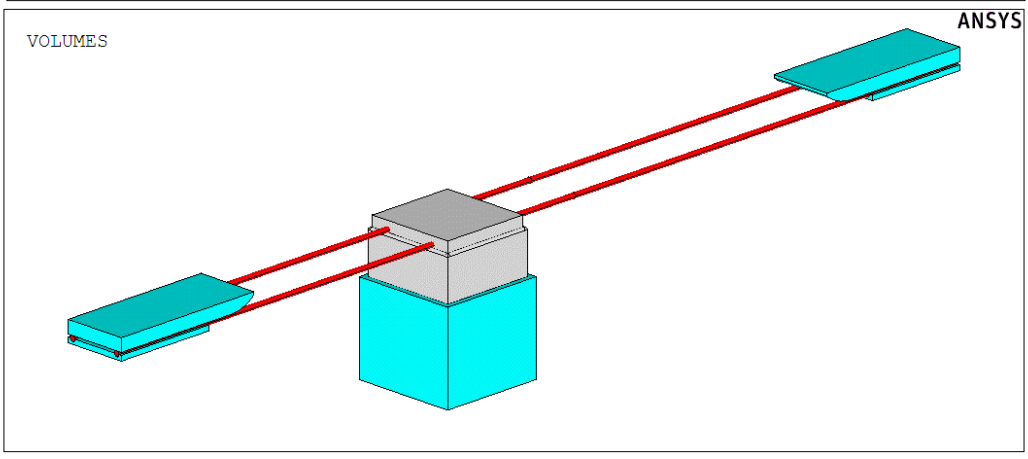

Fig. 1. Types of analyzed numerical models with regard to the column positioned: a) axially, b) eccentrically.

The numerical model consisted of a column element (Fig. 1) with two integrity reinforcement bars passing through. The ends of those rods were immobilized in supports. The load was applied at the base of the column, taking into account its location: axial and eccentric. View of the simplified model with the description of elements and materials applied can be found in Fig. 2. The detailed description of the numerical model and its verification based on experimental research is included in papers $[11,12,13]$. 


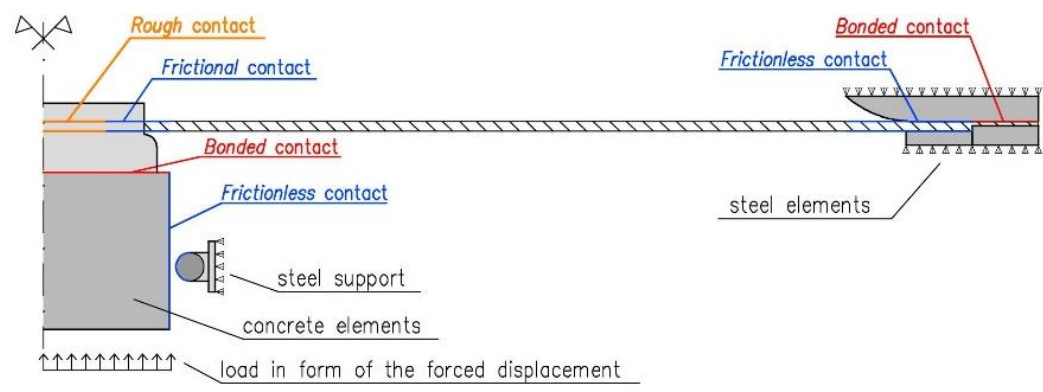

Fig. 2. Scheme of the numerical model - division into elements, contact between elements.

The developed numerical model made it possible to carry out a detailed analysis of the distribution of stresses in individual parts of the integrity reinforcement bar. Moreover, the load-displacement-force dependence was specified. It served as the basis for determining the maximum value of the loading force accompanying the rupture of integrity reinforcement bars. The calculation results were presented and discussed in papers [11, 12,13], along with the reference to guidelines included in standards.

To be able to generalize the analysis conclusions, considerations were necessary for connections with different types of reinforcing steel and diameters of integrity reinforcement bars.

\section{The scope of numerical analysis}

The analysis included the change of values defining the most important parameters of reinforcing steel properties (Fig. 3). Also, parameters directly related to the geometry of the slab-column connection itself were considered (Fig. 4).

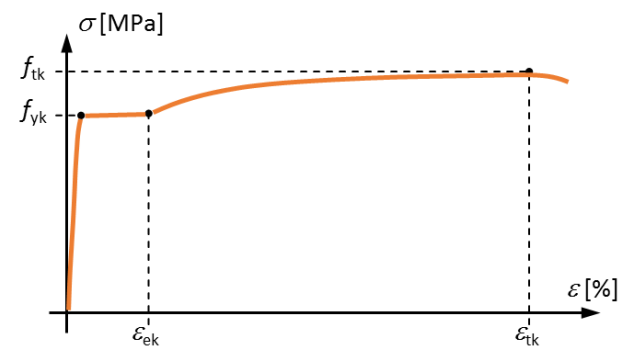

Fig. 3. Designation of parameters defining the $\sigma-\varepsilon$ relation with strengthening.

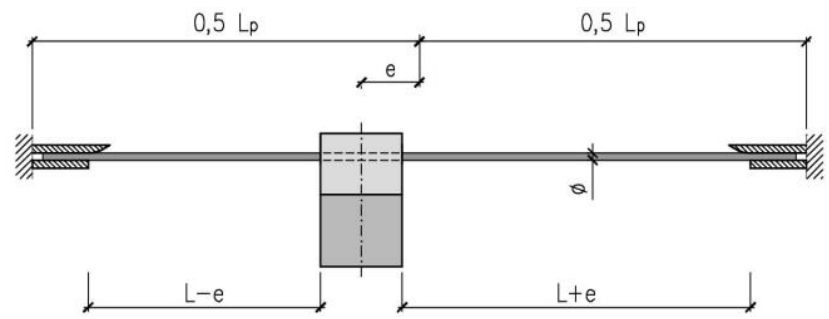

Fig. 4. Designation of parameters describing the bars of integrity reinforcement.

In numerical simulations, the following parameters defining the $\sigma-\varepsilon$ dependence curve of reinforcement steel were assumed for analysis: value of strain at the end of the yield plateau $\varepsilon_{\mathrm{ek}}$ and value of strain at the time of rupture $\varepsilon_{\mathrm{tk}}$, at a fixed yield strength of steel $f_{\mathrm{yk}}$ and ratio of strength against rupture $f_{\mathrm{yt}}$ and yield strength $f_{\mathrm{yk}}$. In addition, the parameters 
defining integrity reinforcement bars were considered: location of load action on bars, length of reinforcing bars between attachment points and diameter of the bars.

Parameters describing the $\sigma-\varepsilon$ curve (Fig. 3) were determined according to the following assumptions. Three values of strain at rupture $\varepsilon_{\mathrm{tk}}$ were defined: $7.5 \%, 15 \%$ and $20 \%$ (marked with A, B and C respectively) and three values of strain at strengthening $\varepsilon_{\mathrm{ek}}$, of $1 \%, 3 \%$ and $5 \%$ (marked with 1, 2 and 3 respectively). In total, 9 curves were obtained. Each of them was considered with the yield strength $f_{\mathrm{yk}}$ of $500 \mathrm{MPa}$ and steel strength against rupture $f_{\text {tk }}$ determined on the basis of strengthening factor $\Delta$ of 1.15 . The graphs $\sigma-\varepsilon$ included in calculations are presented in Fig. 5. The diversification of individual parameters assumed in the analysis corresponded to the requirements which have to be fulfilled by reinforcing steel - class C according to EC2 [2].

a)

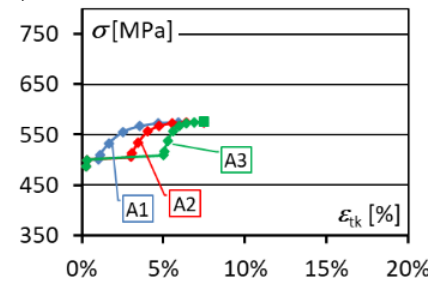

b)

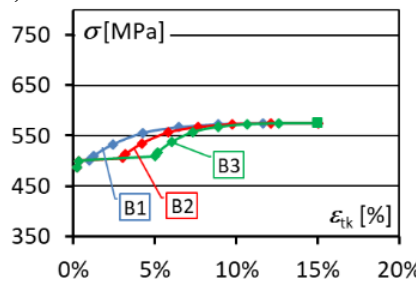

c)

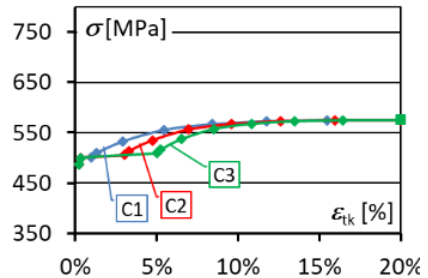

Fig. 5. Summary of curves defining the $\sigma-\varepsilon$ relation according to various $f_{\mathrm{yk}}=500 \mathrm{MPa}$ and $f_{\mathrm{tk}}=1.15 f_{\mathrm{yk}}$ a) $\varepsilon_{\mathrm{tk}}=7.5 \%$, b) $\varepsilon_{\mathrm{tk}}=15 \%$, c) $\varepsilon_{\mathrm{tk}}=20 \%$.

Among the parameters describing integrity reinforcement bars, the length of bars and location of load action on them were considered primarily. The numerical calculations were carried out for $1170 \mathrm{~mm}$ long bars $\varnothing 16 \mathrm{~mm}$, between their attachment points in supports. Two different positions of the column were taken into account: halfway through the span of the bars and at the offset corresponding to $285 \mathrm{~mm}$. This allowed to maintain proportions between the eccentric position of the column and the bar length, which has been taken into account in the analysis.

Numerical simulations were carried out using two types of models: UU-I and UU-II (Fig. 1), with the consideration of the above-mentioned parameters. Because of a considerable number of results and analogical conclusions derived, the results presented below are limited to introducing the most important parameters only. The scope of the analysis focused mainly on comparing the load-bearing capacity of the integrity reinforcement bars, based on the maximum value of force $F_{\max }$ acting on the connection directly before the rupture of the first bar, and the vertical displacement of column $a_{\max }$ corresponding to force $F_{\max }$.

\section{Results of numerical calculations}

Based on the simulations carried out, information was obtained about the change in the force value affecting the connection, depending on the forced vertical displacement of the column. Graphs showing the force-displacement relationship are given in Fig. 6. Summary of forces $F_{\max }$ directly preceding the rupture of the bar, along with the corresponding displacement of column $a_{\max }$, is presented in Table 1 . 
a)

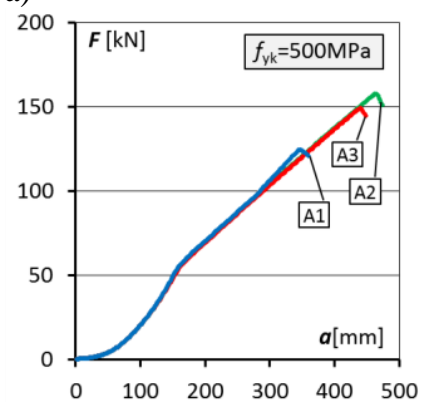

b)

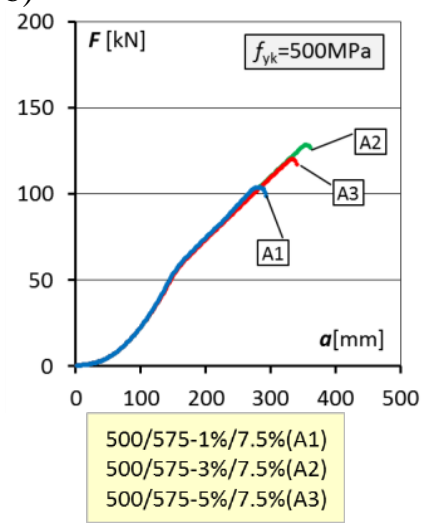

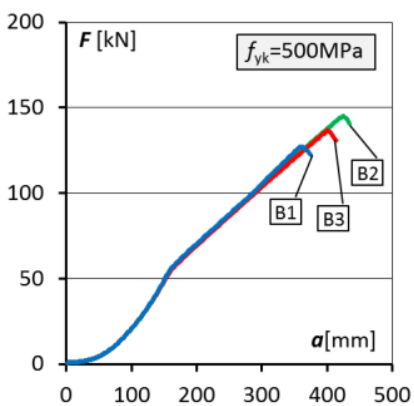
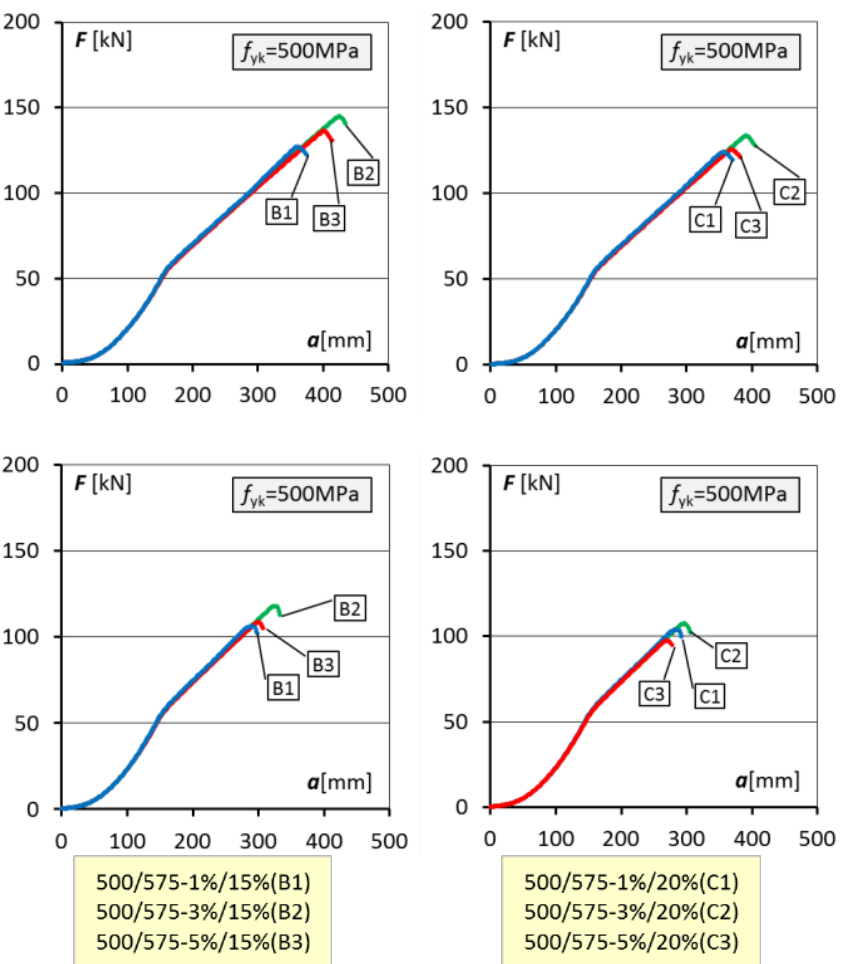

Fig. 6. Diagrams of the force-displacement relation for $f_{\mathrm{tk}}=1.15 f_{\mathrm{yk}}$ and $f_{\mathrm{yk}}=500 \mathrm{MPa}$, taking into account the following eccentric position of the column: a) $0 \mathrm{~mm}$, b) $285 \mathrm{~mm}$.

Table 1. Summary of values $F_{\max }$ and $a_{\max }$, taking into account bars of $f_{\mathrm{tk}} / f_{\mathrm{yk}}=1.15$ and $f_{\mathrm{yk}}=500 \mathrm{MPa}$, with the following eccentric position of the column: $0 \mathrm{~mm}$ and $285 \mathrm{~mm}$.

\begin{tabular}{|c|c|c|c|c|c|c|c|c|c|c|}
\hline \multirow{2}{*}{\multicolumn{2}{|c|}{ Parameters }} & \multicolumn{9}{|c|}{$\sigma-\varepsilon$ dependence curve } \\
\hline & & \multirow{2}{*}{$\frac{\mathbf{A 1}}{1 \%}$} & \multirow{2}{*}{$\frac{\mathbf{A 2}}{3 \%}$} & \multirow{2}{*}{$\frac{\mathbf{A 3}}{5 \%}$} & \multirow{2}{*}{$\frac{\mathbf{B 1}}{1 \%}$} & \multirow{2}{*}{$\frac{\text { B2 }}{3 \%}$} & \multirow{2}{*}{$\frac{\mathbf{B 3}}{5 \%}$} & \multirow{2}{*}{$\frac{\mathbf{C 1}}{1 \%}$} & \multirow{2}{*}{$\frac{\mathbf{C 2}}{3 \%}$} & \multirow{2}{*}{$\begin{array}{c}\mathbf{C 3} \\
5 \%\end{array}$} \\
\hline$e$ & $\varepsilon_{\mathrm{ek}}[\%]$ & & & & & & & & & \\
\hline$[\mathrm{mm}]$ & $\varepsilon \mathrm{k}[\%]$ & $7.5 \%$ & $7.5 \%$ & $7.5 \%$ & $15 \%$ & $15 \%$ & $15 \%$ & $20 \%$ & $20 \%$ & $20 \%$ \\
\hline \multirow{2}{*}{0} & $F_{\max }[\mathrm{kN}]$ & 124.1 & 157.5 & 148.9 & 126.4 & 144.5 & 135.9 & 123.6 & 133.2 & 125.0 \\
\hline & $a_{\max }[\mathrm{mm}]$ & 347 & 465 & 440 & 362 & 425 & 401 & 357 & 392 & 369 \\
\hline \multirow{2}{*}{285} & $F_{\max }[\mathrm{kN}]$ & 103.4 & 128.3 & 120.0 & 105.8 & 117.7 & 108.1 & 103.7 & 107.2 & 97.2 \\
\hline & $a_{\max }[\mathrm{mm}]$ & 280 & 354 & 333 & 291 & 327 & 303 & 287 & 299 & 273 \\
\hline
\end{tabular}

The greatest load-bearing capacity of the connection was obtained in the model in which the relationship $\sigma-\varepsilon$ according to the A2 curve was assumed, where the length of the plastic shelf corresponded to the strain at strengthening $\varepsilon_{\mathrm{ek}}=3 \%$, and the maximum steel strain at rupture was $\varepsilon_{\mathrm{tk}}=7.5 \%$ (Fig. 7). Also, in this case the highest value of column displacement, occurring at the at rupture of bar was obtained (Fig. 8). Values of $F_{\max }$ forces between individual models differed to $21.5 \%$ at the axial location of the column. However, in models 
with a column shifted on the eccentric they amounted to $24.2 \%$ and $25.8 \%$ respectively. Differences in the value of displacement of the column amax obtained for individual models did not exceed $26 \%$. Thus, the values of the strain $\varepsilon_{\mathrm{ek}}$ and $\varepsilon_{\mathrm{ek}}$ characterizing the reinforcing steel had a significant impact on the results obtained.

a)

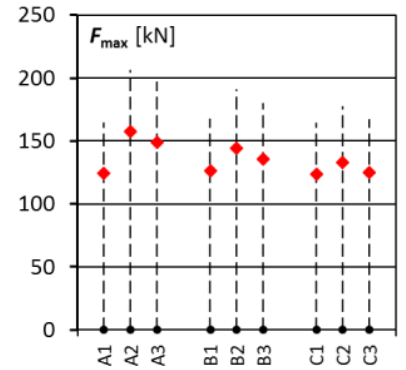

b)

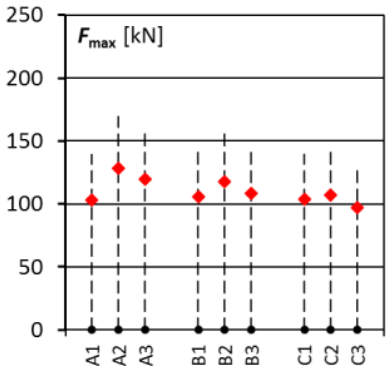

Fig. 7. Summary of values of $F_{\max }$ forces for $f_{\mathrm{tk}}=1.15 f_{\mathrm{yk}}$ and $f_{\mathrm{yk}}=500 \mathrm{MPa}$, taking into account the following eccentric position of the column: a) $0 \mathrm{~mm}$, b) $285 \mathrm{~mm}$.

a)

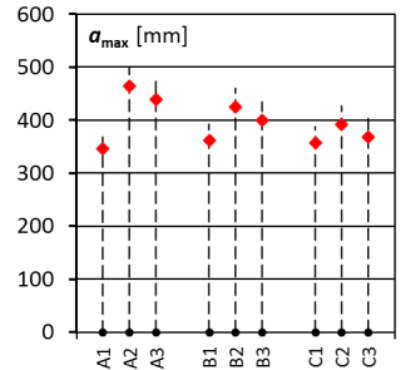

b)

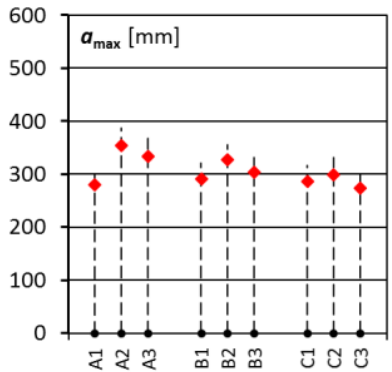

Fig. 8. Summary of values of $a_{\max }$ column displacements for $f_{\mathrm{tk}}=1.15 f_{\mathrm{yk}}$ and $f_{\mathrm{yk}}=500 \mathrm{MPa}$, taking into account the following eccentric position of the column: a) $0 \mathrm{~mm}$, b) $285 \mathrm{~mm}$.

Based on the value of column displacements $a_{\max }$, the values of bar inclination angles $\alpha_{\max }$ were determined, relative to their original horizontal position (Table 2). The values of the bar inclination angle $\alpha_{\max }$ ranged from $16^{\circ}$ to $21^{\circ}$ in models with an axially located column, while from $17^{\circ}$ to $22^{\circ}$ with its displacement on the eccentric (Fig. 9). The relative deformation of the bars $\varepsilon_{\max }$ at the length between the cross-sections in which they were bent was also determined (Table 2). In the ruptured bar, its value ranged from $4.5 \%$ to $7.4 \%$. Slightly higher values of strain $\varepsilon_{\max }$ occurred in the case of models in which $\varepsilon_{\mathrm{tk}}=7.5 \%$ (models according to curves A1, A2 and A3) than in the others (Fig. 10). At the eccentric position of the column, the deformation of the longer bar reached a maximum value of $2.5 \%$, with an eccentric equal to $285 \mathrm{~mm}$.

a)

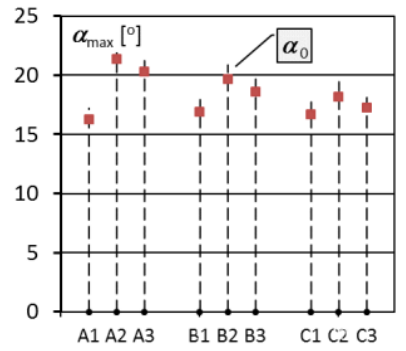

b)

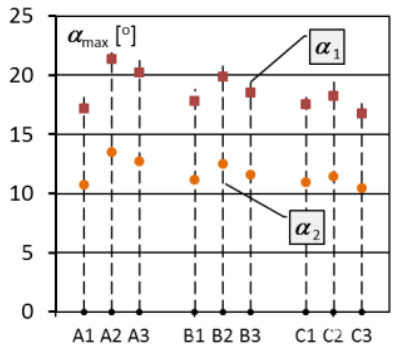

Fig. 9. Summary of values of $\alpha_{\mathrm{max}}$ bar inclination angles for $f_{\mathrm{tk}}=1.15 f_{\mathrm{yk}}$ and $f_{\mathrm{yk}}=500 \mathrm{MPa}$, taking into account the following eccentric position of the column: a) $0 \mathrm{~mm}$, b) $285 \mathrm{~mm}$. 
a)

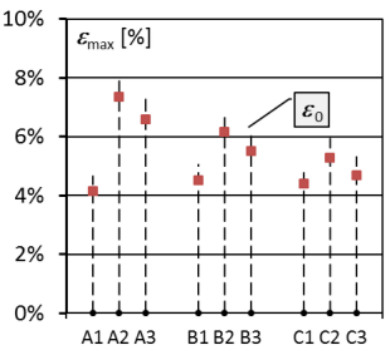

b)

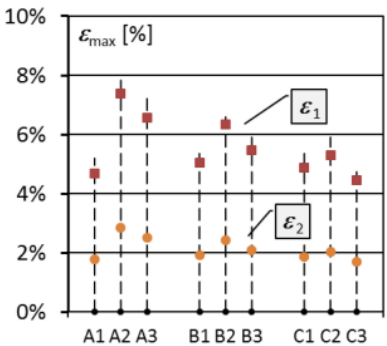

Fig. 10. Summary of values of $\varepsilon_{\max }$ bar strains for $f_{\mathrm{tk}}=1.15 f_{\mathrm{yk}}$ and $f_{\mathrm{yk}}=500 \mathrm{MPa}$, taking into account the following eccentric position of the column: a) $0 \mathrm{~mm}$, b) $285 \mathrm{~mm}$.

Table 2. Summary of values $\alpha_{\max }$ and $\varepsilon_{\max }$, at $f_{\mathrm{tk}}=1.15 f_{\mathrm{yk}}$ and $f_{\mathrm{yk}}=500 \mathrm{MPa}$

- models with eccentric position of the column equal $0 \mathrm{~mm}$ and $285 \mathrm{~mm}$.

\begin{tabular}{|c|c|c|c|c|c|c|c|c|c|c|}
\hline \multirow{2}{*}{\multicolumn{2}{|c|}{ Parameters }} & \multicolumn{9}{|c|}{$\sigma-\varepsilon$ dependence curve } \\
\hline & & \multirow{2}{*}{$\begin{array}{l}\mathbf{A 1} \\
1 \%\end{array}$} & \multirow{2}{*}{$\begin{array}{l}\mathbf{A 2} \\
3 \%\end{array}$} & \multirow{2}{*}{$\begin{array}{l}\mathbf{A 3} \\
5 \%\end{array}$} & \multirow{2}{*}{$\begin{array}{l}\text { B1 } \\
1 \%\end{array}$} & \multirow{2}{*}{$\begin{array}{l}\mathbf{B 2} \\
3 \%\end{array}$} & \multirow{2}{*}{$\begin{array}{l}\mathbf{B 3} \\
5 \%\end{array}$} & \multirow{2}{*}{$\frac{\mathbf{C 1}}{1 \%}$} & \multirow{2}{*}{$\begin{array}{l}\text { C2 } \\
3 \%\end{array}$} & \multirow{2}{*}{$\begin{array}{l}\mathbf{C 3} \\
5 \%\end{array}$} \\
\hline$e$ & $\varepsilon_{\mathrm{ek}}[\%]$ & & & & & & & & & \\
\hline [mm] & $\varepsilon_{\mathrm{k}}[\%]$ & $7.5 \%$ & $7.5 \%$ & $7.5 \%$ & $15 \%$ & $15 \%$ & $15 \%$ & $20 \%$ & $20 \%$ & $20 \%$ \\
\hline \multirow{2}{*}{0} & $\alpha_{1, \max }\left[{ }^{\circ}\right]$ & 16.2 & 21.3 & 20.3 & 16.9 & 19.6 & 18.6 & 16.7 & 18.2 & 17.2 \\
\hline & $\varepsilon_{1, \text { max }}[\%]$ & 4.15 & 7.36 & 6.60 & 4.51 & 6.17 & 5.51 & 4.40 & 5.27 & 4.70 \\
\hline \multirow{4}{*}{285} & $\alpha_{1, \max }\left[^{\circ}\right]$ & 17.2 & 21.4 & 20.2 & 17.8 & 19.9 & 18.5 & 17.6 & 18.3 & 16.8 \\
\hline & $\alpha_{2, \max }\left[{ }^{\circ}\right]$ & 10.8 & 13.5 & 12.7 & 11.2 & 12.5 & 11.6 & 11.0 & 11.4 & 10.5 \\
\hline & $\mathcal{E}_{1, \max }[\%]$ & 4.68 & 7.38 & 6.55 & 5.04 & 6.33 & 5.46 & 4.89 & 5.30 & 4.45 \\
\hline & $\varepsilon_{2, \max }[\%]$ & 1.79 & 2.84 & 2.52 & 1.93 & 2.43 & 2.09 & 1.87 & 2.03 & 1.70 \\
\hline
\end{tabular}

\subsection{Changes strain at strengthening}

In the case of models in which the relationship $\sigma-\varepsilon$, was adopted, where the length of the plastic shelf was $1 \%$ (models according to the curve A1, B1 and C1), the load capacity of the connection was at the same level, regardless of the value of strain at rupture $\varepsilon_{\mathrm{tk}}$ (Fig. 11). The differences in the $F_{\max }$ force values ranged from $0.8 \%$ to $2.3 \%$, regardless of the column position.

In the models in which $\varepsilon_{\mathrm{ek}}=3 \%$ (models according to curve A2, B2 and C2), the highest load-bearing capacity was obtained when the $\varepsilon_{\mathrm{tk}}$ value was assumed equal to $7.5 \%$ (model according to curve A2). At $\varepsilon_{\mathrm{tk}}$ of $15 \%$ (model according to the B2 curve), the load-bearing capacity of the connection was reduced by $8.7 \% \div 10.6 \%$, while at $\varepsilon_{\mathrm{tk}}=20 \%$ (model according to the $\mathrm{C} 3$ curve) it was lower by a further $7.4 \% \div 10.1 \%$.

Similar observations concerned the models in which $\varepsilon_{\mathrm{ek}}=5 \%$ (models according to curves A3, B3 and C3). Here, too, the largest load-bearing capacity of the connection was obtained at $\varepsilon_{\mathrm{tk}}=7.5 \%$ (model according to curve A3). The decrease of its value occurred by $9.6 \% \div 13.3 \%$ and additionally by $7.9 \% \div 10.4 \%$, respectively, with $\varepsilon_{\mathrm{tk}}$ equal to $15 \%$ (model 
according to curve B3) and $20 \%$ (model according to curve C3). In addition, the load-bearing carrying capacities of these connections were $3.4 \%$ to $4.6 \%$ lower compared to the corresponding models according to curves A2, B2 and C2. The above regularities occurred in both the axial and eccentric position of the column.

a)

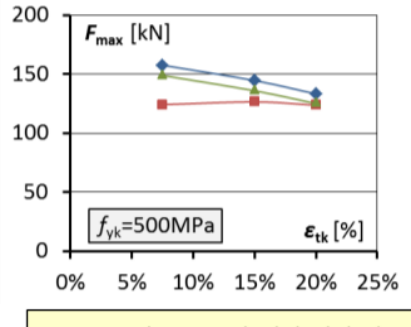

b)

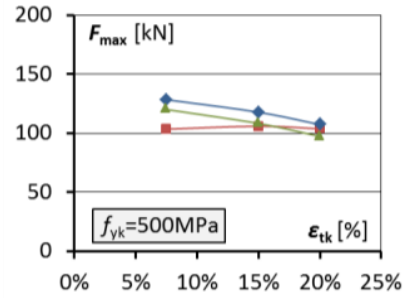

$\rightarrow-\varepsilon \mathrm{ek}=1 \% \rightarrow(\mathrm{A} 1),(\mathrm{B} 1),(\mathrm{C} 1)$

$\rightarrow-\varepsilon \mathrm{ek}=3 \% \rightarrow(\mathrm{A} 2),(\mathrm{B} 2),(\mathrm{C} 2)$

$\rightarrow-\varepsilon \mathrm{ek}=5 \% \rightarrow(\mathrm{A} 3),(\mathrm{B} 3),(\mathrm{C} 3)$

Fig. 11. Summary of values of $F_{\max }$ forces depending on the values of $\varepsilon_{\mathrm{tk}}$ strain for $f_{\mathrm{tk}}=1.15 f_{\mathrm{yk}}$ and $f_{\mathrm{yk}}=500 \mathrm{MPa}$, taking into account the following eccentric position of the column: a) $\left.0 \mathrm{~mm}, \mathrm{~b}\right) 285 \mathrm{~mm}$.

Similar relationships were observed in the range of displacement of the column $a_{\max }$, corresponding to the obtained values of forces $F_{\max }$ (Fig. 12).

a)

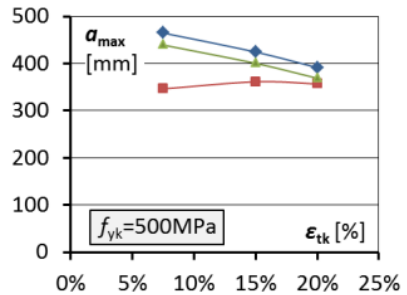

b)

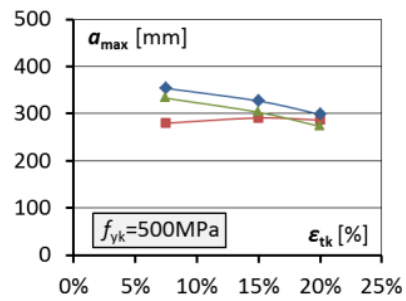

$$
\rightarrow-\varepsilon e k=1 \% \rightarrow \text { (A1), (B1), (C1) } \rightarrow \text { - eek=3\% > (A2), (B2), (C2) } \rightarrow \text { eek=5\% } \rightarrow \text { (A3), (B3), (C3) }
$$

Fig. 12. Summary of values of $a_{\max }$ column displacements depending on the values of $\varepsilon_{\mathrm{k}}$ strain for $f_{\mathrm{tk}}=1,15 f_{\mathrm{yk}}$ and $f_{\mathrm{yk}}=500 \mathrm{MPa}$, taking into account the following eccentric position of the column: a) $0 \mathrm{~mm}$, b) $285 \mathrm{~mm}$.

\subsection{Changes of maximum elongation at rupture}

The highest load-bearing carrying of connection were obtained in models, in which in dependence $\sigma-\varepsilon$ the strain at rupture $\varepsilon_{\mathrm{tk}}$ was assumed to be $7.5 \%$ (models according to curve A1, A2 and A3. Increasing its value caused a decrease of the load-bearing capacity of the connection (Fig. 13). In models in which the total elongation at rupture $\varepsilon_{\mathrm{tk}}$ was assumed to be $15 \%$ and $20 \%$, the decrease of their load-bearing capacity was $9.1 \% \div 10.6 \%$ and respectively $18.3 \% \div 22.8 \%$ at $\varepsilon_{\mathrm{ek}}=3 \%$ (models according to $\mathrm{B} 2$ and $\mathrm{B} 3$ curve) and $9.6 \% \div 13.3 \%$ and $19.1 \% \div 25.6 \%$ respectively, with $\varepsilon_{\mathrm{ek}}=5 \%$ (models according to the $\mathrm{C} 2$ and $\mathrm{C} 3$ curves). However, at $\varepsilon_{\mathrm{ek}}=1 \%$ (models according to curve A1, B1 and $\mathrm{C} 1$ ), the load-bearing capacity of the connections remained at the same level, regardless of the total elongation $\varepsilon_{\mathrm{t} k}$. The above regularities occurred regardless of the location of the column.

In the case of displacement of the column $a_{\max }$, corresponding to the obtained values of forces $F_{\max }$, analogous relationships occurred (Fig. 14). 
a)

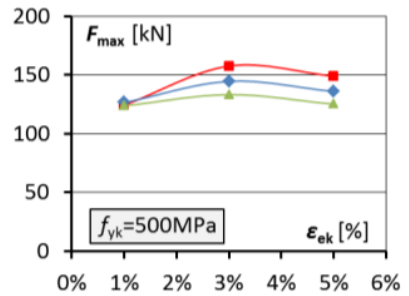

b)

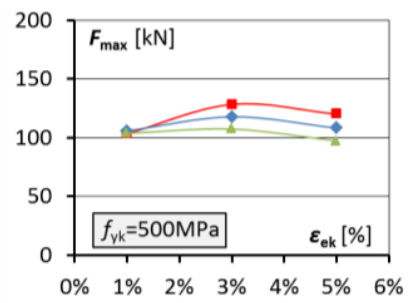

$-=-\varepsilon t k=7,5 \%->(A 1),(\mathrm{A} 2),(\mathrm{A} 3)$

$\rightarrow-\varepsilon \mathrm{tk}=15 \% \rightarrow(\mathrm{B} 1),(\mathrm{B} 2),(\mathrm{B} 3) \quad \rightarrow-\mathrm{tk}=20 \% \rightarrow(\mathrm{C} 1),(\mathrm{C} 2),(\mathrm{C} 3)$

Fig. 13. Summary of values of $F_{\mathrm{max}}$ forces depending on the values of $\varepsilon_{\mathrm{ek}}$ strain for $f_{\mathrm{tk}}=1,15 f_{\mathrm{yk}}$ and $f_{\mathrm{yk}}=500 \mathrm{MPa}$, taking into account the following eccentric position of the column: a) $0 \mathrm{~mm}$, b) $285 \mathrm{~mm}$.

a)

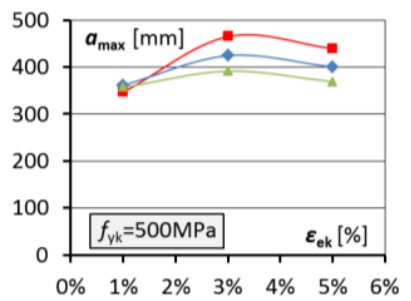

b)

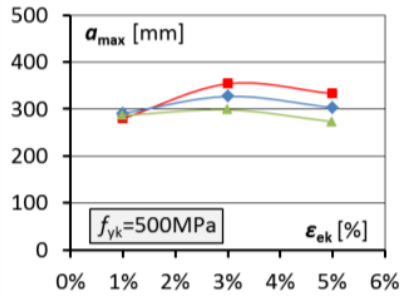

Fig. 14. Summary of values of $a_{\max }$ column displacements depending on the value of $\varepsilon_{\mathrm{ek}}$ strain for $f_{\mathrm{tk}}=1.15 f_{\mathrm{yk}}$ and $f_{\mathrm{yk}}=500 \mathrm{MPa}$, taking into account the following eccentric position of the column: a) $0 \mathrm{~mm}$, b) $285 \mathrm{~mm}$.

\subsection{Conclusions}

At a strain $\varepsilon_{\mathrm{ek}}$ of $1 \%$, the increase in strain value at break $\varepsilon_{\mathrm{tk}}$ from $7.5 \%$ to $20 \%$ did not change the load-bearing capacity of the connection, which remained at the same level. Increasing the value of strain $\varepsilon_{\mathrm{ek}}$ to $3 \%$ caused an increase in the load-bearing capacity of the connection, which was particularly visible at $\varepsilon_{\mathrm{tk}}=7.5 \%$, and slightly smaller at $\varepsilon_{\mathrm{tk}}=15 \%$. Further elongation of the plastic shelf no longer resulted in an increase in the value of $F_{\max }$. On the contrary it was smaller than at $\varepsilon_{\mathrm{ek}}=3 \%$. In addition, at $\varepsilon_{\mathrm{tk}}=20 \%$, adopting different values of strain $\varepsilon_{\mathrm{ek}}$ did not practically affect the load-bearing capacity of the connection. At the same time, it was noticed that the differences in the maximum values of forces $F_{\max }$ obtained for individual models, with the eccentric position of the column, were smaller than with its axial position.

Increasing the strain at rupture $\varepsilon_{\mathrm{tk}}$ from $7.5 \%$ to $20 \%$ resulted in a reduction of the connection load-bearing capacity to $18.3 \% \div 20.6 \%$, wherein its size depending on the strain $\varepsilon_{\text {ek }}$. With a strain $\varepsilon_{\text {ek }}$ equal to $1 \%$, the change in the load-bearing capacity of the connection was practically zero, and with its increase to $3 \%$ and $5 \%$, it was decreased.

\section{Summary}

The numerical analysis made it possible to determine the impact of the individual mechanical and geometric parameters of the reinforcing steel on the load bearing capacity of the integrity reinforcement, and thus on the post-punching load-bearing capacity of the slab-column connection. The analysis was carried out using the numerical model that had been verified with experimental research $[11,12,13]$. Among the parameters analyzed (yield strength 
of reinforcing steel, ratio of strength against rupture $f_{\mathrm{yt}}$ and yield strength $f_{\mathrm{yk}}$, value of strain at the end of the yield plateau, value of strain at the time of rupture, location of load action on bars, length of reinforcing bars between attachment points), the change of the diameter of the integrity reinforcement bars turned out to be the most important one. One of the main conclusions drawn from analysis was the observation that assuming the greater diameters of the integrity bars, and thus increasing the cross-section area of the reinforcement, did not have proportional impact on the increment of the load-bearing capacity of integrity reinforcement bars in a slab-column connection. The bigger the increase of the cross-section of bars $A_{\mathrm{sb}}$ became, the smaller the increase of maximum force value $F_{\max }$ was. This pointed at the reduction in the load-bearing capacity with regard to the diameter of the bars applied. The detailed analysis of stresses proved that the increase in the diameter of the bars was accompanied by the increased contribution of normal stresses resulting from the bending of the bar compared to normal stresses resulting from the axial tensioning of the bar.

\section{References}

1. EN 1991-1-7:2008 - Eurocode 1 - Actions on structures - Part 1-7: General actions Accidental actions (2008)

2. PN-EN 1992-1-1:2008 - Eurocode 2: Design of concrete structures - Part 1-1: General rules and rules for buildings (2008)

3. W. Starosolski, B. Wieczorek, M. Wieczorek: Technical Bulletin, 6, Steel Quality Promotion Center, Warsaw (2015)

4. B. Wieczorek: Procedia Engineering, 57 (2013)

5. B. Wieczorek: Applied Mechanics and Materials, 837 (2016)

6. J. Cervenka, V.K. Papanikolaou: International Journal of Plasticity, 24, 12 (2008)

7. O. Sucharda, J. Brozovsky, D. Mikolasek: Key Engineering Materials, 577-578 (2014)

8. K.J. Willam, T. Tanabe: Finite element analysis of reinforced concrete structures, ACI International, Special Publication SP-205 (2001)

9. K.J. Willam, E.P. Warnke: Proceedings of the International Association for Bridge and Structural Engineering, 19, ISMES, May 17-19, Bergamo, Italy (1975)

10. E.L. Wilson, R.L. Taylor, W.P. Doherty, J. Ghaboussi: Incompatible displacement models, Numerical and Computer Methods in Structural Mechanics, Academic Press Inc., New York \& London (1973)

11. B. Wieczorek: Procedingds of $20^{\text {th }}$ International Conference "Engineering Mechanics", (2014)

12. B. Wieczorek: Applied Mechanics and Materials, 769 (2015)

13. B. Wieczorek: Procedia Engineering, 190 (2017) 